\title{
Tingkat pemahaman taktik dan strategi pemain sepakbola
}

\author{
The level of understanding of football players' tactics and strategies
}

\author{
Kartono Pramdhan $^{1}$, Taufiq Ahmad Tarmizi ${ }^{2}$, Papat Yunisal ${ }^{3}$ \\ 1,2,3 Program studi PJKR, STKIP Pasundan, Cimahi, Jawa Barat, 40513, Indonesia
}

\begin{abstract}
Abstrak
Penelitian ini bertujuan untuk mengetahui seberapa tinggi tingkat pemahaman taktik dan strategi pemain sepakbola. Penelitian ini merupakan penelitian deskriptif kuantitatif dengan teknik pengumpulan data berupa tes pengetahuan kepada 24 pemain Football Education Sanggarung U-20. Instrumen yang digunakan berupa angket atau kuesioner yang berisi pernyataan-pernyataan tentang taktik dan strategi. Untuk menganalisis data digunakan teknik deskriptif. Hasil penelitian memperlihatkan bahwa pemahaman taktik dan strategi pemain sepakbola masuk dalam kategori "sedang". Maka dari itu, dapat ditarik kesimpulan bahwa perlu adanya peningkatan kemampuan pemahaman taktik dan strategi pemain sepakbola agar bisa lebih berprestasi dan bermain di level professional.
\end{abstract}

Kata kunci: pemahaman taktik, strategi, sepakbola.

\begin{abstract}
This study aims to determine how high the level of understanding of tactics and strategies of soccer players. This research is a quantitative descriptive study with data collection techniques in the form of knowledge tests to 24 Football Education Sanggarung U-20 players. The instrument used was a questionnaire or questionnaire containing statements about tactics and strategy. To analyze the data used descriptive techniques. The results showed that the understanding of tactics and strategies of soccer players included in the category of "medium". Therefore, it can be concluded that there needs to be an increase in the ability of football players to understand tactics and strategies so that they can perform more and play at a professional level.
\end{abstract}

Keywords: understanding of tactics, strategy, football..

\section{PENDAHULUAN}

Saat ini perkembangan permainan sepakbola di Indonesia sangatlah pesat, hal ini ditandai dengan banyaknya kompetisi sepakbola yang diadakan, mulai dari pertandingan tingkat daerah hingga pertandingan tingkat nasional maupun internasional. Prinsip dasar dalam permainan sepakbola sederhana, tujuan dari permainan sepakbola adalah masing-

Correspondence author: Kartono Pramdhan/Taufiq Ahmad Tarmizi/Papat Yunisal, STKIP Pasundan, Indonesia.

Email: kartonopramdhan.04@gmail.com, taufiqahmadtarmizi@gmail.com 
masing regu atau kesebelasan yaitu berusaha menguasai bola, memasukan bola ke dalam gawang lawan sebanyak mungkin, dan berusaha mematahkan serangan lawan untuk melindungi atau menjaga gawangnya agar tidak kemasukan bola.

Dalam olahraga prestasi, untuk memenangkan sebuah pertandingan diperlukan sebuah kematangan fisik, teknik, strategi/taktik serta mental . Aspek fisik, pemain yang kuat dan ulet akan memberikan keuntungan yang besar untuk tim. Kemudian teknik, semua pemain di dalam tim diharuskan memiliki kemampuan individu yang sesuai dengan posisi masing-masing. Setelah memiliki teknik merata maka dibutuhkan penguasaan taktik. Bagian ini sangat membantu pemain agar menyatu dengan tim. Tujuannya adalah untuk menghasilkan pemain yang cerdas, mampu beradaptasi dalam situasi yang berganti-ganti dalam pertandingan-pertandingan yang dihadapi.

Maka dari itu, dalam mengajarkan permainan sepakbola perlu diberikan pengetahuan akan keseluruhan aspek tersebut. Aspek-aspek yang paling banyak diberikan kepada pemain adalah aspek fisik dan teknik.

Taktik dan strategi sekilas nampak sama hanya berbeda dalam hal waktu penerapannya. Strategi diterapkan pada sebelum pertandingan sedangkan taktik dilakukan pada saat pertandingan. Dalam permainan sepakbola, taktik dan strategi dalam bertanding sangat diperlukan guna untuk mencapai tujuan yaitu memenangkan pertandingan. Salah satu syarat untuk bermain sepakbola dengan baik adalah pemain harus mampu melakukan aksi-aksi sepakbola dalam setiap momen (Danurwindo et al., 2017).

Aksi-aksi sepakbola dalam momen menyerang selalu di awali dengan fase membangun serangan, baik aksi dengan bola seperti dribble, passing, control, crossing, heading. Juga aksi tanpa bola seperti menciptakan ruang, berlari ke ruang, support. Setelah tim membangun serangan maka tim menyelasaikannya. Untuk menyelasaikan serangan, terdapat aksi sepakbola seperti shooting dan heading. Dalam momen bertahan, dimulai dari fase ganggu lawan bangun serangan. Aksi sepakbola yang dilakukan pada fase ini adalah pressing, marking, covering, tackling, squeeze space. Kemudian pada fase cegah lawan selesesaikan serangan, aksi sepakbola yang dilakukan diantaranya blocking, deflecting, catching-punching-tipping (kiper).

Football Education Sanggarung U-20 merupakan sebuah klub pendidikan sepakbola yang telah berdiri selama 3 tahun, adanya Sanggarung U-20 bermula dari turnamen sepakbola yang pernah diadakan di Kelurahan Citangtu, Kecamatan-Kabupaten Kuningan. Setelah selesainya turnamen tersebut dibentuklah klub pendidikan sepakbola yang bertujuan untuk menampung pemain-pemain sepakbola U-20 di Kelurahan Citangtu untuk meningkatkan bakat dan pemahaman mengenai sepakbola. 
Pada bulan Februari 2019 Football Education Sanggarung U-20 ikut serta dalam Liga Gocek 2019 Zona Kuningan. Dari hasil analisis dalam pertandingan, terdapat permasalahan mengenai taktik dan strategi yaitu kurangnya komunikasi antar pemain dalam menjalankan taktik dan strategi yang telah disepakati pelatih dan pemain pada saat pertandingan berlangsung. Seperti yang sering terjadi pada fase dan momen bangun serangan (build up) dari belakang, gelandang menempati ruang antar lini, kedua fullback yang melebar dan tinggi. Namun tidak ada dinamika pemosisian terkait opsi yang perlu mereka berikan terhadap bek tengah ketika mendapat tekanan dari lawan sehingga mekanisme progresi menjadi tidak optimal. Pada saat kehilangan bola pemain seperti kebingungan antara langsung merebut bola (gegenpressing) untuk kembali menguasai bola atau membentuk blok pertahanan (press build up), bahkan pemain sisi jauh hanya melihat ke arah mana bola (ball watching) dialirkan oleh lawan sehingga terjadi disorganisasi struktur pada saat bertahan.

Di samping hal tersebut terdapat juga permasalahan yang berkaitan dengan pola permainan yang dilakukan dalam bermain. Yaitu formasi tim sesuai strategi yang digunakan dan disepakti bersama. Dalam hal itu seharusnya pemain sudah memahami pola permainan dasar 1-4-3-3. Berdasarkan uraian tersebut, maka penulis berminat untuk melakukan penelitian yang berjudul "Tingkat Pemahaman Taktik dan Strategi Pemain Sepakbola".

\section{METODE}

Metode yang dipergunakan dalam penelitan ini yaitu metode deskriptif kuantitatif dengan pendekatan survei dan teknik pengumpulan data menggunakan tes benar-salah. Populasi dalam penelitian ini adalah seluruh pemain Football Education Sanggarung U20 yang berjumlah 24 pemain. Teknik pengambilan sampel dalam penelitian ini menggunakan total sampling (Sugiyono, 2017). Dalam penelitian ini jumlah anggota populasi sebanyak 24 pemain, dengan demikian jumlah sampel yang digunakan adalah 24 pemain.

Untuk mendapatkan data mengenai tingkat pengetahuan taktik dan strategi pemain menggunakan angket atau kuesioner yang berisi pernyataan-pernyataan tentang taktik dan strategi dengan dua alternatif jawaban, yaitu: Benar (B) dan Salah (S) "Titik tolak dari penyusunan instrumen adalah variabel-variabel penelitian yang ditetapkan untuk diteliti. Dari variabel-variabel tersebut diberikan definisi operasionalnya, dan selajutnya ditentukan indikator yang akan diukur. Kemudian setelah semua data terkumpul, langkah selanjutnya adalah menganalisis data sehingga data-data tersebut dapat ditarik suatu 
kesimpulan. Teknik analisis data dalam penelitian ini menggunakan teknik analisis data deskriptif kuantitatif. Cara perhitungan analisis data mencari besarnya frekuensi relatif persentase (Anas, 2011). Adapun kisi-kisi angket pada penelitian ini dapat dilihat pada tabel sebagai berikut:

Tabel 1. Kisi-kisi angket

\begin{tabular}{cclcc}
\hline Faktor & \multicolumn{1}{c}{ Indikator } & \multicolumn{2}{c}{ Item } \\
& & & $(+)$ & $(-)$ \\
\hline Taktik & 1. & Pengertian taktik & 1,2 & \\
& 2. & Ciri-ciri penggunaan taktik & 3,6 & 4,5 \\
& 3. & Taktik individu & 7 & 8 \\
& 4. & Taktik tim/regu & & \\
& 5. & Manfaat taktik & 9 & 10 \\
& 6. & Faktor yang di pertimbangkan dalam bertindak & 12 & 11 \\
& 7. & Waktu penerapan & 13 & 14 \\
& 8. & Bentuk penerapan taktik & 15,16 & \\
\hline Strategi & 1. & Pengertian Strategi & 17,18 & 19 \\
& 2. & Mengingat penggunaan strategi & $20,21,22$ & \\
& 3. & Strategi Jangka panjang dan jangka pendek & 24 & 23,25 \\
& 4. & Strategi subjektif & 26,28 & 27 \\
& 5. & Ciri-ciri penggunaan strategi & 29,30 & 32 \\
& 6. & Peran dominan & 31 & \\
& 7. & Formasi & 33 & 34 \\
& 8. & Pola permainan & 35 & 36 \\
& & & 37 & 38 \\
\hline
\end{tabular}

\section{HASIL DAN PEMBAHASAN}

\section{Hasil}

Hasil penelitian ini dimaksudkan untuk menggambarkan data yaitu tentang seberapa tinggi tingkat pemahaman taktik dan strategi pemain sepakbola, yang diungkapkan dalam tes yang berjumlah 35 butir, dan terbagi dalam 2 faktor, yaitu (1) pengertian taktik dan (2) pengertian strategi. Hasil analisis data penelitian ini tingkat pemahaman pemain tentang taktik dan strategi pemain sepakbola dipaparkan sebagai berikut:

\section{Faktor Pemahaman tentang Taktik}

Deskriptif statistik data hasil penelitian tentang tingkat pemahaman pemain terhadap taktik dalam bermain sepakbola. Apabila ditampilan menurut distribusi frekuensi, pada pemain Football Education Sanggarung U-20 sebagai berikut: 
Tabel 2. Deskripsi Statistik Tingkat Pemahaman Taktik Pemain Sepakbola

\begin{tabular}{lr}
\hline & Statistik \\
\hline$N$ & 24 \\
Mean & 14.5417 \\
Median & 14.5 \\
Mode & 16 \\
Std. Deviation & 1.81729 \\
Maximum & 18 \\
Minimum & 10 \\
\hline
\end{tabular}

Berdasarkan tabel di atas, tingkat pemahaman pemain Football Education Sanggarung U-20 tentang taktik dalam permainan sepakbola dengan jumlah 24 pemain memiliki rata-rata sebesar 14.54, nilai tengah sebesar 14.5, nilai yang sering muncul sebesar 16, simpangan baku sebesar 1.81, skor tertinggi sebesar 18, dan skor terendah sebesar 10. Untuk mempermudah klasifikasi kategori pemahaman, peneliti sebelumnya menentukan interval kelas. Adapun kualitas pemahaman pemain tentang taktik sepakbola yang dimaksud adalah rendah, sedang dan tinggi. Setelah dilakukan perhitungan maka data dapat didistribusikan sebagaimana tabel di bawah ini:

Tabel 3. Distribusi Frekuensi Pemahaman Taktik Pemain Sepakbola

\begin{tabular}{ccccc}
\hline No & Interval & Kategori & Frekuensi & Persentase \\
\hline 1 & $>16.36$ & Tinggi & 3 & $13 \%$ \\
2 & $12.72-16.36$ & Sedang & 19 & $79 \%$ \\
3 & $<12.72$ & Rendah & 2 & $8 \%$ \\
\hline & Jumlah & & 24 & $100 \%$ \\
\hline
\end{tabular}

Tabel di atas menunjukkan distribusi skor penilaian kategori pemahaman pemain tentang taktik sepakbola yang terdiri dari 24 pemain. Berdasarkan tabel di atas dari total pemain yang terlibat, tiga pemain (13\%) termasuk pada kategori tinggi. Adapun 19 pemain $(79 \%)$ termasuk pada kategori sedang. Sedangkan sisanya dua pemain $(8 \%)$ memiliki kualitas yang rendah. Maka dapat disimpulkan bahwa pemahaman pemain Football Education Sanggarung U-20 terhadap taktik dalam permainan sepakbola berada pada kategori sedang. Perbedaan hasil tersebut dapat dilihat dalam diagram batang tingkat pemahaman taktik pemain sepakbola di Football Education Sanggarung U-20 sebagai berikut: 


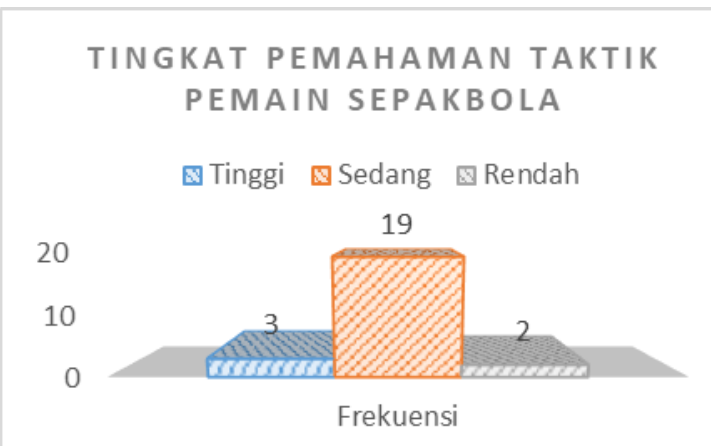

Gambar 1. Grafik Tingkat Pemahaman Taktik Pemain Sepakbola

2. Faktor Pemahaman Strategi

Berikut ini merupakan hasil analisis data penelitian mengenai pemahaman strategi pemain sepakbola. Apabila ditampilan menurut distribusi frekuensi, pada pemain Footbal Education Sanggarung U-20 sebagai berikut:

Tabel 4. Deskripsi Statistik Tingkat Pemahaman Strategi Pemain Sepakbola

\begin{tabular}{lr}
\hline & Statistik \\
\hline$N$ & 24 \\
Mean & 13.0833 \\
Median & 13 \\
Mode & 13 \\
Std. Deviation & 1.95419 \\
Maximum & 17 \\
Minimum & 10 \\
\hline
\end{tabular}

Berdasarkan tabel tersebut, tingkat pemahaman pemain Football Education Sanggarung U-20 tentang strategi sepakbola dengan jumlah 24 pemain memiliki rata-rata sebesar 13.08, nilai tengah sebesar 13 , nilai yang sering muncul sebesar 13 , simpangan baku sebesar 1.95, skor tertinggi sebesar 17, dan skor terendah sebesar 10. Untuk mempermudah klasifikasi kategori pemahaman, peneliti sebelumnya menentukan interval kelas. Adapun kualitas pemahaman pemain tentang strategi sepakbola yang dimaksud adalah rendah, sedang dan tinggi. Setelah dilakukan perhitungan maka data dapat didistribusikan sebagaimana tabel di bawah ini:

Tabel 5. Distribusi Frekuensi Pemahaman Strategi Pemain Sepakbola

\begin{tabular}{|c|c|c|c|c|}
\hline No & Interval & Kategori & Frekuensi & Persentase \\
\hline 1 & $>15.04$ & Tinggi & 4 & $17 \%$ \\
\hline 2 & $11.13-15.04$ & Sedang & 15 & $63 \%$ \\
\hline 3 & $<11.13$ & Rendah & 5 & $21 \%$ \\
\hline \multicolumn{3}{|c|}{ Jumlah } & 24 & $100 \%$ \\
\hline
\end{tabular}


Tabel di atas menunjukkan distribusi skor penilaian kategori pemahaman pemain tentang strategi sepakbola yang terdiri dari 24 pemain. Berdasarkan tabel di atas dari total pemain yang terlibat, empat pemain (17\%) termasuk pada kategori tinggi. Adapun 15 pemain (63\%) termasuk pada kategori sedang. Sedangkan sisanya lima pemain $(21 \%)$ memiliki kualitas yang rendah. Maka dapat disimpulkan bahwa pemahaman pemain Football Education Sanggarung U-20 tentang strategi sepakbola berada pada kategori sedang. Perbedaan hasil tersebut dapat dilihat dalam diagram batang tingkat pemahaman pemain tentang strategi sepakbola di Football Education Sanggarung sebagai berikut:

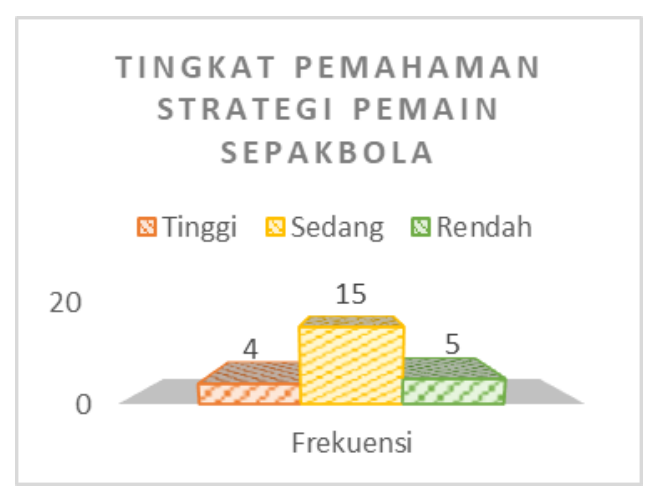

Gambar 2. Grafik Tingkat Pemahaman Strategi Pemain Sepakbola

3. Pemahaman Taktik dan Strategi

Hasil analisis data penelitian mengenai pemahaman taktik dan strategi pemain sepakbola. Apabila ditampilan menurut distribusi frekuensi, pada pemain Football Education Sangarung U-20 sebagai berikut:

Tabel 6. Deskripsi Statistik Tingkat Pemahaman Taktik dan Strategi Pemain Sepakbola

\begin{tabular}{lr}
\hline & Statistik \\
\hline$N$ & 24 \\
Mean & 27.625 \\
Median & 27.5 \\
Mode & 26 \\
Std. Deviation & 2.82554 \\
Maximum & 33 \\
Minimum & 21 \\
\hline
\end{tabular}

Berdasarkan tabel di atas, tingkat pemahaman pemain Football Education Sanggarung U-20 tentang taktik dan strategi sepakbola dengan jumlah 24 pemain memiliki rata-rata sebesar 27.625, nilai tengah sebesar 27.5, nilai yang sering muncul sebesar 26, simpangan baku sebesar 2.82, skor tertinggi sebesar 33, dan skor terendah sebesar 21. Untuk mempermudah klasifikasi kategori pemahaman, peneliti sebelumnya menentukan interval kelas. Adapun kualitas pemahaman pemain tentang taktik dan 
strategi sepakbola yang dimaksud adalah rendah, sedang dan tinggi. Setelah dilakukan perhitungan maka data dapat didistribusikan sebagaimana tabel berikut ini:

Tabel 7. Distribusi Frekuensi Pemahaman Taktik dan Strategi Pemain Sepakbola

\begin{tabular}{ccccc}
\hline No & Interval & Kategori & Frekuensi & Persentase \\
\hline 1 & $>30.45$ & Tinggi & 4 & $17 \%$ \\
2 & $24.80-30.45$ & Sedang & 18 & $75 \%$ \\
3 & $<24.80$ & Rendah & 2 & $8 \%$ \\
\hline & Jumlah & & 24 & $100 \%$
\end{tabular}

Tabel di atas menunjukkan distribusi skor penilaian kategori pemahaman pemain tentang taktik dan strategi sepakbola yang terdiri dari 24 pemain. Berdasarkan tabel di atas dari total pemain yang terlibat, empat pemain (17\%) termasuk pada kategori tinggi. Adapun 18 pemain (75\%) termasuk pada kategori sedang. Sedangkan sisanya dua pemain (8\%) memiliki kualitas yang rendah. Maka dapat disimpulkan bahwa pemahaman pemain Football Education Sanggarung U-20 tentang taktik dan strategi dalam bermain sepakbola berada pada kategori sedang. Perbedaan hasil tersebut dapat dilihat dalam diagram batang tingkat pemahaman pemain tentang taktik dan strategi sepakbola di Football Education Sanggarung U-20 sebagai berikut:

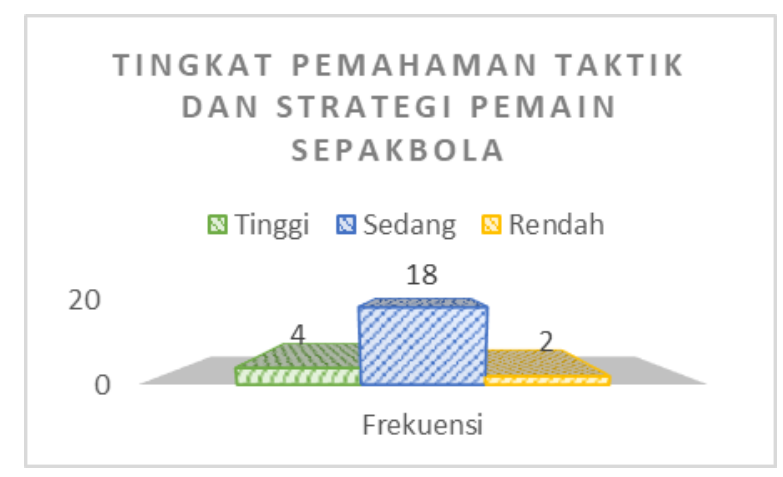

Gambar 3. Grafik Tingkat Pemahaman Taktik dan Strategi Pemain Sepakbola

\section{Pembahasan}

Penelitian ini bertujuan untuk mengetahui pemahaman taktik dan strategi pemain sepakbola. Secara lebih rinci dijelaskan sebagai berikut:

1. Pemahaman Tentang Taktik

Berdasarkan hasil analisis menunjukkan bahwa pemahaman pemain Football Education Sanggarung U-20 tentang taktik secara keseluruhan masuk dalam kategori "sedang". Dari hasil analisis pemahaman pemain Football Education Sanggarung U-20 tentang taktik termasuk pada kategori tinggi sebesar 13\% (3 pemain). Artinya hanya 3 pemain dari 24 pemain yang pemahamannya sudah bagus tentang taktik sepakbola, 
pemain sudah mengetahui tentang ciri-ciri penggunaan taktik, pemain juga dapat membedakan antara taktik individu dan taktik tim, manfaat dari taktik itu sendiri dalam sebuah pertandingan.

Dari hasil analisis pemahaman pemain Football Education Sanggarung U-20 tentang taktik sepakbola termasuk pada kategori sedang sebesar 79\% (19 pemain), artinya ada 19 pemain dari 24 pemain antara tidak tahu dan tahu tentang pengertian dari taktik, perbedaan taktik dan ciri-ciri penggunaan taktik. Pemain cukup tahu mengenai ciri-ciri taktik yang mengembangkan daya kreatif dalam pengambilan keputusan yang tepat, tetapi sebagian pemain belum mengerti tentang perbedaan taktik individu dan taktik tim sepakbola.

Dari hasil analisis pemahaman pemain Football Education Sanggarung U-20 tentang taktik sepakbola termasuk pada kategori rendah sebesar 8\% (2 pemain), artinya 2 pemain dari 24 pemain masih rendah tentang taktik sepakbola, pemain tidak mengetahui tentang ciri-ciri penggunaan taktik, misalnya pemain tidak mengetahui bahwa taktik seharusnya diterapkan pada saat pertandingan berlangsung. Pemain juga kurang dapat membedakan antara taktik individu dan taktik tim.

Pemahaman yang baik tentang taktik sepakbola diperoleh dengan tahap-tahap tertentu. Tahap tersebut adalah tahap persepsi, tahap analisis, tahap penyelesaian secara mental, dan tahap penyelesaian secara motoris (Pekik, 2002). Tiap tahap memerlukan kematangan, pengalaman, dan analisis yang cermat baik dari pelatih dan pemain. Maka untuk meningkatkan pemahaman tentang taktik Pemahaman yang baik tentang taktik sepakbola diperoleh dengan tahap-tahap tertentu.

Pemahaman taktik sepakbola juga dipengaruhi oleh beberapa aspek, yaitu seperti kondisi fisik, kemampuan teknik, stabilitas mental dan kecerdasan pemain (Siswanto \& Budi, 2012). Pemain yang memiliki taktik yang baik berarti memiliki daya nalar, kreatif, dan cepat dalam mengambil keputusan. Selain itu juga didukung oleh kualitas fisik, teknik dan mental bermain yang baik.

\section{Pemahaman Tentang Strategi}

Berdasarkan hasil analisis menunjukkan bahwa pemahaman pemain Football Education Sanggarung U-20 tentang strategi sepakbola masuk dalam kategori "sedang “. Pemahaman tentang strategi sepakbola pemain Football Education Sanggarung U-20 masuk dalam kategori tinggi sebesar 17\% (4 pemain), artinya hanya 4 pemain dari 24 pemain yang pemahaman strategi dalam kategori baik. Pemain sudah mengerti tentang pengertian strategi, cara penggunaan strategi dalam permainan, ciri-ciri penggunaan strategi. 
Pemahaman tentang strategi sepakbola pemain Football Education Sanggarung U20 masuk dalam kategori sedang sebesar 63\% (15 pemain), artinya 15 pemain dari 24 pemain yang mempunyai pemahaman tentang strategi dalam kategori sedang. Ada pemain yang memahami tentang pengertian strategi dan pemain mampu mengingat penggunaan strategi dalam permainan, namun pemain kurang mengetahui perbedaan strategi jangka panjang dan strategi jangka pendek.

Pemahaman tentang strategi sepakbola pemain Football Education Sanggarung U20 masuk dalam kategori rendah sebesar 21\% (5 pemain), artinya 5 pemain dari 24 pemain belum mengetahui tentang pengertian strategi dan penggunaan strategi dalam permainan, serta pemain juga kurang mengetahui perbedaan strategi jangka panjang dan strategi jangka pendek. Strategi merupakan pola atau rencana yang mengintegrasikan tujuan utama atau kebijakan dengan rangkaian tindakan dalam sebuah pernyataan yang saling mengikat (Wibisono, 2006). Pemahaman yang baik tentang strategi dari seorang pemain sepakbola diperoleh dari kemampuan individu pemain dalam merespon kondisi sebelum pertandingan dan materi strategi yang diberikan oleh pelatih. Semakin cepat pemain dalam merespon situasi sebelum pertandingan dengan sebuah rencana yang tepat berarti semakin baik pemahaman pemain terhadap strategi (Brito E Sousa et al., 2019; Fashioni et al., 2020; Goes et al., 2020; Thomas et al., 2020; Young et al., 2020).

\section{Pemahaman Taktik dan Strategi}

Berdasarkan hasil anilisis mengenai tingkat pemahaman pemain tentang taktik dan strategi sepakbola dengan frekuensi 18 pemain (75\%). Adapun pemain yang berada dalam kategori tinggi berjumlah 4 pemain atau (17\%) dan yang berada dalam kategori rendah berjumlah dua orang atau $8 \%$. Maka dapat disimpulkan bahwa pemahaman pemain Football Education Sanggarung U-20 terntang taktik dan strategi sepakbola berada pada kategori "sedang".

Pemahaman adalah kemampuan seseorang untuk mengerti atau memahami sesuatu setelah sesuatu itu diketahui dan diingat, dengan kata lain, memahami adalah mengetahui sesuatu dan dapat melihatnya dari berbagai segi. Seseorang dikatakan memahami sesuatu apabila ia dapat memberikan penjelasan atau memberi uraian lebih rinci tentang hal itu dengan menggunakan kata-katanya sendiri (Anas, 2011). Sejalan dengan pendapat tersebut menunjukkan bahwa pemain Football Education Sanggarung U-20 berusaha untuk mencerna dan memahami tentang taktik dan strategi sepakbola untuk digunakan dalam pertandingan. Akan tetapi, kondisi di lapangan menunjukkan bahwa pemain belum bisa memahami secara baik tentang taktik dan strategi sehingga pemain masih diperlukan latihan tambahan untuk meningkatkan pemahaman taktik dan strategi sepakbola. 
Pada dasarnya dalam bermain sepakbola tidak hanya dilihat pada aspek fisik dan mental saja tetapi pemahaman terhadap taktik dan pemahaman strategi juga diperlukan (Lastella et al., 2020; Machado et al., 2019; Young et al., 2020). Berdasarkan penggunaannya, taktik dibedakan menjadi 3 yaitu: taktik individu (diterapkan oleh individu/pemain dalam menghadapi situasi-situasi dalam permainan), taktik unit (diterapkan oleh tiap-tiap unit permainan (belakang, tengah, dan depan) dalam menghadapi situasi-situasi dalam permainan), dan taktik beregu (diterapkan oleh regu/tim dalam menghadapi situasi-situasi dalam permainan).Hal ini membuktikan bahwa taktik/strategi dan mental merupakan bagian penting dalam permainan sepakbola. Strategi dalam sepakbola dibedakan menjadi 2 yaitu strategi penyerangan dan strategi pertahanan (Komarudin, 2005).

Oleh karena sangat pentingnya taktik dan strategi dalam bermain sepakbola, maka dari itu seorang pelatih sangat diharuskan untuk memberikan pemahaman dalam bentuk teori maupun praktek dalam bentuk-bentuk latihan tentang taktik dan strategi dalam bermain sepakbola kepada para pemainnya.

\section{KESIMPULAN}

Berdasarkan hasil penelitian dan pembahasan yang telah dipaparkan maka dapat diambil kesimpulan bahwa tingkat pemahaman taktik dan strategi pemain sepakbola di Football Education Sanggarung U-20 dalam kategori "sedang". Dengan Tingkat pemahaman pemain tentang taktik dan strategi sepakbola dengan frekuensi 18 pemain (75\%). Adapun pemain yang berada dalam kategori tinggi yaitu berjumlah 4 pemain atau $(17 \%)$ dan yang berada dalam kategori rendah berjumlah dua orang atau $8 \%$.

\section{DAFTAR PUSTAKA}

Anas, S. (2011). Pengantar Evaluasi Pendidikan. Raja Rafindo Persada.

Brito E Sousa, R., Bredt, S. D. G. T., Greco, P. J., Manuel Clemente, F., Teoldo, I., \& Praça, G. M. (2019). Influence of limiting the number of ball touches on players' tactical behaviour and network properties during football small-sided games. International Journal of Performance Analysis in Sport, 19(6), 999-1010. https://doi.org/10.1080/24748668.2019.1689751

Danurwindo, Putera, G., \& Sidik, B. (2017). Kurikulum Pembinaan Sepakbola Indonesia. $1-11$.

Fashioni, E., Langley, B., \& Page, R. M. (2020). The effectiveness of a practical halftime re-warm-up strategy on performance and the physical response to soccerspecific activity. Journal of Sports Sciences, 38(2), 140-149. https://doi.org/10.1080/02640414.2019.1686941 
Goes, F. R., Meerhoff, L. A., Bueno, M. J. O., Rodrigues, D. M., Moura, F. A., Brink, M. S., Elferink-Gemser, M. T., Knobbe, A. J., Cunha, S. A., Torres, R. S., \& Lemmink, K. A. P. M. (2020). Unlocking the potential of big data to support tactical performance analysis in professional soccer: A systematic review. European Journal of Sport Science, $\quad 0(0), \quad 1-16$. https://doi.org/10.1080/17461391.2020.1747552

Komarudin. (2005). Dasar Gerak Sepakbola. Universitas Negeri Yogyakarta.

Lastella, M., Escobar, L., Lovell, G., Scanlan, A., Ellison, E., McGowan, L., \& Guy, J. (2020). An exploration of goal scoring strategies in an elite beach soccer tournament. Science and Medicine in Football, $O(0), \quad 1$. https://doi.org/10.1080/24733938.2020.1758759

Machado, J. C., Barreira, D., Teoldo, I., Travassos, B., Júnior, J. B., Santos, J. O. L. Dos, \& Scaglia, A. J. (2019). How Does the Adjustment of Training Task Difficulty Level Influence Tactical Behavior in Soccer? Research Quarterly for Exercise and Sport, 90(3), 403-416. https://doi.org/10.1080/02701367.2019.1612511

Pekik, D. (2002). Dasar Kepelatihan Olahraga. Universitas Negeri Yogyakarta.

Siswanto, A., \& Budi, M. (2012). Taktik, Strategi, dan Formasi. http://cillasmartlucky.blogspot.com/2012/04/taktik-strategi-dan-formasi.html

Sugiyono. (2017). Metode Penelitian Kuantitatif, Kualitatif dan R\&D. Alfabeta.

Thomas, C., Dos'santos, T., Cuthbert, M., Fields, C., \& Jones, P. A. (2020). The effect of limb preference on braking strategy and knee joint mechanics during pivoting in female soccer players. Science and Medicine in Football, 4(1), 30-36. https://doi.org/10.1080/24733938.2019.1667020

Wibisono, D. (2006). Manajemen Kerja. Erlangga.

Young, C. M., Luo, W., Gastin, P. B., \& Dwyer, D. B. (2020). Understanding the relative contribution of technical and tactical performance to match outcome in Australian Football. Journal of Sports Sciences, 38(6), 676-681. https://doi.org/10.1080/02640414.2020.1724044 